\title{
FAT1: a potential target for monoclonal antibody therapy in colon cancer
}

\author{
Piero Pileri ${ }^{1,8}$, Susanna Campagnoli ${ }^{1,8}$, Alberto Grandi ${ }^{1,8}$, Matteo Parri ${ }^{1,8}$, Elisa De Camilli ${ }^{2}$, Chaojun Song $^{3}$, \\ Luisa Ganfini ${ }^{1}$, Aurelien Lacombe ${ }^{4}$, Ilaria Naldi ${ }^{5}$, Paolo Sarmientos ${ }^{1}$, Caterina Cinti ${ }^{5}$, Boquan Jin $^{3}$, \\ Guido Grandi ${ }^{1,6}$, Giuseppe Viale ${ }^{2,7}$, Luigi Terracciano ${ }^{4}$ and Renata Grifantini ${ }^{*, 1}$ \\ ${ }^{1}$ Externautics SpA, Siena, Italy; ${ }^{2}$ European Institute of Oncology, Milan, Italy; ${ }^{3}$ The Fourth Military Medical University, Xi'an, China; \\ ${ }^{4}$ Medical Center, Basel University, Basel, Switzerland; ${ }^{5}$ IFC-CNR, Siena, Italy; ${ }^{6}$ University of Trento, Trento, Italy and ${ }^{7}$ University of \\ Milan, Milan, Italy
}

Background: Colorectal cancer (CRC) is one of the major causes of cancer-associated mortality worldwide. The currently approved therapeutic agents have limited efficacy.

Methods: The atypical cadherin FAT1 was discovered as a novel CRC-associated protein by using a monoclonal antibody (mAb198.3). FAT1 expression was assessed in CRC cells by immunohistochemistry (IHC), immunoblots, flow cytometry and confocal microscopy. In addition, in vitro and in vivo tumour models were done to assess FAT1 potential value for therapeutic applications.

Results: The study shows that FAT1 is broadly expressed in primary and metastatic CRC stages and detected by mAb198.3, regardless of KRAS and BRAF mutations. FAT1 mainly accumulates at the plasma membrane of cancer cells, whereas it is only marginally detected in normal human samples. Moreover, the study shows that FAT1 has an important role in cell invasiveness while it does not significantly influence apoptosis. mAb198.3 specifically recognises FAT1 on the surface of colon cancer cells and is efficiently internalised. Furthermore, it reduces cancer growth in a colon cancer xenograft model.

Conclusions: This study provides evidence that FAT1 and mAb198.3 may offer new therapeutic opportunities for CRC including the tumours resistant to current EGFR-targeted therapies.

Colorectal cancer $(\mathrm{CRC})$ is the fourth leading cause of cancerrelated mortality worldwide, accounting for over 600000 deaths annually (Ferlay et al, 2010). The 5 -year survival is $90 \%$ in early stages and drops to $\sim 10 \%$ if metastasis has occurred (O'Connell et al, 2004). Metastatic patients treated with chemotherapy have a mean survival of $\sim 12$ months. Cetuximab and Panitumumab monoclonal antibodies (mAbs) used in combination with chemotherapy to treat advanced CRC patients achieve an overall survival benefit of $\sim 5$ months (Ciardiello et al, 1991; Hagan et al, 2013). However, CRC with mutations in V-Ki-ras2 Kirsten rat sarcoma viral oncogene homolog (KRAS) and v-Raf murine sarcoma viral oncogene homolog $\mathrm{B}(B R A F)$ are resistant to treatment with the anti-EGFR antibodies (Hagan et al, 2013). Overall, the currently approved therapeutic regimens have limited efficacy. Therefore, the identification of other markers targetable by specific mAbs is essential to improve survival of CRC patients.

Following our immunohistochemistry (IHC) approach to discover novel tumour markers (Grifantini et al, 2011; Parri et al, 2014), we identified a mAb directed against FAT1 that stained specifically and with high-frequency CRC cells.

Human FAT1 is a type 1 transmembrane protein belonging to the FAT gene family. It is composed of 34 cadherin repeats, 5 EGFlike repeats, a laminin $\mathrm{A}-\mathrm{G}$ domain in the extracellular region and

\footnotetext{
*Correspondence: Dr R Grifantini; E-mail: renata.grifantini@externautics.com

${ }^{8}$ These authors contributed equally to this work.
}

Revised 19 April 2016; accepted 27 April 2016; published online 21 June 2016

(c) 2016 Cancer Research UK. All rights reserved 0007-0920/16 
a cytoplasmic tail (Dunne et al, 1995). FAT1 undergoes proteolytic cleavages to release an intracellular domain (ICD), which is able to translocate into the nucleus (Magg et al, 2005). FAT1 ICD also interacts with $\beta$-catenin and prevents its translocation into the nucleus (Morris et al, 2013a). In addition, it interacts with Ena/ VAPS and Scribble (Moeller et al, 2004; Tanoue and Takeichi, 2004), promotes actin-mediated cell migration and inhibits YAP1mediated cell proliferation (Moeller et al, 2004).

The role of FAT1 is highly debated, being reported as a tumour suppressor (Settakorn et al, 2005; Nakaya et al, 2007; Chosdol et al, 2009) or a tumour promoter (de Bock et al, 2012). FAT1 has been reported to undergo an aberrant processing in melanoma and pancreatic cancer (Sadeqzadeh et al, 2011; Wojtalewicz et al, 2014).

In this study, we demonstrate that FAT1 is associated with CRC, being expressed and localised at the level of the plasma membrane in a large fraction of early- and late-stage CRC, as well as in lowand high-grade CRC, with a statistical association with stage pT1 and grade 1 CRC. Remarkably, FAT1 is detected in CRC, regardless of the presence of mutations in KRAS and BRAF genes. The protein is also expressed in a significant fraction of colon adenomas, but generally confined to the cytoplasm. Moreover, we show that mAb198.3 binds the surface of different FAT1-positive colon cancer cell lines and it is efficiently internalised, a property that makes it suitable for the development of antibody-drug conjugates (ADC) for CRC therapy. Finally, naked mAb198.3 also shows antitumour activity in a mouse xenograft model of human colon cancer. Overall, the study provides proof of concept that FAT1 and mAb198.3 could be exploited for the treatment of CRC, and may offer new therapeutic opportunities for KRAS- and BRAFmutated CRC refractory to current EGFR-based targeted therapies.

\section{MATERIALS AND METHODS}

Reagents and cell cultures. Unless specified, all reagents were obtained from Sigma (St Louis, MO, USA). mAb198.3 was selected against a recombinant FAT1 region (amino acids (aa) 723-1352), using the hybridoma technology (Song et al, 2009). His-tagged recombinant FAT1 domains were generated in Escherichia coli as described (Grifantini et al, 2011). Human cells were obtained from ATCC (Manassas, VA, USA) and cultured under recommended conditions. Peripheral blood lymphocytes were isolated from whole blood of three human donors using the Ficoll-Paque method (GE Healthcare, Chicago, IL, USA).

IHC analysis. Tissue microarray preparation, IHC staining and analysis were performed essentially as described previously (Kononen et al, 1998; Tornillo et al, 2007; Grifantini et al, 2011). Briefly, formalin-fixed, paraffin-embedded tissue blocks of CRC resections and normal samples were retrieved from the archives of the Institute of Pathology, University Hospital Basel and the Institute of Clinical Pathology, Basel, Switzerland. Colorectal cancer and normal samples were arrayed in parallel on the same TMA slides and analysed simultaneously. One tissue cylinder with a diameter of $0.6 \mathrm{~mm}$ was punched from morphologically representative tissue areas, mostly central tumour areas and rather away from the infiltrating tumour border. In addition, a TMA containing 159 colon adenoma of various histological grade, including 29 villous, 63 tubular and 68 tubular-villous adenoma, as well as 74 corresponding normal colon tissue samples, was also analysed. Clinicopathologic data for all samples were obtained from archives. The study was approved by the Human Research Ethic Committee of the University Hospital of Basel (Ethikkommission Nord-und Zentralschweiz, reference number EK 322/13). Finally, a commercial TMA (MNO961; Pantomics, Richmond, CA, USA) carrying normal samples from 33 organs was also used to assess FAT1 staining. Slides were screened semiquantitatively for the percentage and the intensity of the signal for FAT1. At least 100 cells were counted for each punch. Intensity of the signal was graded semiquantitatively in four groups from 0 (no positivity) to 3 (strong positivity). A case was considered low positive if it showed a positive signal between $10 \%$ and $33 \%$ of cells, moderate positive between $33 \%$ and $66 \%$ and strong positive $>66 \%$. Negative control samples were prepared by using an irrelevant isotype control antibody and/or by omitting the primary antibody.

Cell transfection. Transfection was assessed as described (Grifantini et al, 2011) using sequence-verified pcDNA3.1D (Invitrogen, Carlsbad, CA, USA) derivative plasmids encoding different overlapping domains of FAT1 (aa 723-1352).

Western blot analysis. Cell monolayers were detached with PBS-0.5 mM EDTA and subjected to western blot (WB) with mAb198.3 or an anti-actin Ab, using a previously described protocol (Grifantini et al, 2011).

FACS analysis. Cells $\left(2 \times 10^{4} /\right.$ well $)$ were pelletted in 96 U-bottom microplates and incubated for $1 \mathrm{~h}$ at $4{ }^{\circ} \mathrm{C}$ with the appropriate dilutions of mAb198.3. Cells were washed two times in PBS-5\% FCS and incubated for $20 \mathrm{~min}$ with R-phycoerythrin (PE)conjugated secondary antibody (Jackson ImmunoResearch, West Grove, PA, USA) at $4{ }^{\circ} \mathrm{C}$. Cells were analysed by a FACS-Canto-II flow cytometer (BD Biosciences, San Jose, CA, USA) and data were analysed with the FlowJo (Ashland, OR, USA) software.

Confocal microscopy. Cells were plated on microscope coverslips, stained with mAb198.3 $\left(10 \mu \mathrm{g} \mathrm{ml}^{-1}\right)$, using a previously described protocol, without permeabilisation (Grifantini et al, 2011). For detection, AlexaFluor 488-labelled goat anti-mouse antibodies and DAPI were used. For colocalisation analysis, cells were simultaneously labelled with mAb198.3 and anti-E-cadherin or anti- $\beta$-catenin rabbit antibodies and detected with AlexaFluor 594-labelled goat anti-mouse or AlexaFluor 488-labelled goat antirabbit antibodies.

FAT1 silencing. FAT1 was silenced in colon cancer cell lines with commercially available FAT1-specific siRNAs (10 nM) or irrelevant siRNA and the HiPerfect transfection reagent (Qiagen, Venlo, Netherlands) following the manufacturer's protocol. After $48 \mathrm{~h}$, loss of FAT1 expression was analysed by qRT-PCR, WB and FACS. Quantitative reverse transcription-PCR was performed with commercially available FAT1 primers (Qiagen) as described previously (Parri et al, 2014).

Phenotypic assays. Cell invasiveness was assessed by the Boyden chamber assay. Cells (2000/well) were placed onto Matrigel-coated 24-well plates, and, after $\mathrm{ON}$ incubation at $37^{\circ} \mathrm{C}$, non-invading cells were removed mechanically using cotton swabs, and microporous membrane containing the invaded cells was fixed in 96\% methanol and stained with Diff-Quick staining solutions. Invasiveness was evaluated by counting the cells that migrated towards the lower surface of the filters (10 randomly chosen fields for each filter). Each experiment was carried out in triplicate and averaged from at least three independent experiments.

Antibody internalisation and drug screening assay. For FACS analysis, cells were incubated with the mAb198.3 $\left(10 \mu \mathrm{g} \mathrm{ml}^{-1}\right)$ or a $\mathrm{mAb}$ against the surface marker CD81 as an internal control for $30 \mathrm{~min}$ at $4{ }^{\circ} \mathrm{C}$, then washed with PBS-5\% FCS and finally shifted to $37^{\circ} \mathrm{C}$. At time points, cells were incubated for $20 \mathrm{~min}$ with PEconjugated secondary antibody at $4{ }^{\circ} \mathrm{C}$ and the residual binding was analysed as described above. For confocal microscopy analysis, cells were incubated with mAb198.3 for $1 \mathrm{~h}$ at $4{ }^{\circ} \mathrm{C}\left(10 \mu \mathrm{g} \mathrm{ml}^{-1}\right)$, shifted at $37^{\circ} \mathrm{C}$, fixed with $90 \%$ cold methanol and stained as described (Grifantini et al, 2011). For the indirect ADC killing assay, cells were seeded in 96-well cell culture plates (2000 cells per well) and incubated for $72 \mathrm{~h}$ at $37^{\circ} \mathrm{C}$ with mAb198.3 (3-80 nM) in 
the presence of $20 \mathrm{~nm}$ Protein G-MCC-DM1 (Concortis, San Diego, CA, USA). Cell killing was assessed by luminescence reading (Cell Titer Glo; Promega, Madison, WI, USA). Data are presented as means \pm s.d. from at least three independent experiments. Enzyme-linked immunosorbent assay Enzyme-linked immunosorbent assay plates (NuncMaxisorp; Sigma Aldrich, St Louis, MO, USA) were coated with $1 \mu \mathrm{g}$ of His-tagged FAT1 recombinant domains in $\mathrm{PBS}(\mathrm{pH} 7.4)$ at $4{ }^{\circ} \mathrm{C}$ overnight. After washing, cells were treated for $1 \mathrm{~h}$ at $37^{\circ} \mathrm{C}$ with PBS-1\% BSA, and incubated for $2 \mathrm{~h}$ with different dilutions of mAb198.3 in PBS$0.1 \%$ Tween. Later, the plates were washed and incubated for $1 \mathrm{~h}$ at $37^{\circ} \mathrm{C}$ with alkaline-phosphatase-conjugated goat anti-mouse IgG. Thereafter, $100 \mu \mathrm{l}$ of PNPP substrate was added to the samples and incubated for $30 \mathrm{~min}$ at room temperature and optical densities were read at $405 \mathrm{~nm}$.

Colon cancer xenograft. HCT15 or HT29 human colon carcinoma cells $\left(5 \times 10^{6}\right)$ were injected subcutaneously into the right flank of nude athymic mice (Harlan Laboratories; 8 mice per group). Mice were treated intravenously with repeated doses of either mAb198.3 or an irrelevant IgG1k isotype control (300 $\mu \mathrm{g}$ per dose, equal to $12 \mathrm{mg} \mathrm{kg}^{-1}$ of animal weight, 2 doses per week starting from day -1 before injection of CRC cells in the preventive model, or starting when the tumour reached $100 \mathrm{~mm}^{3}$ in the therapeutic model, or untreated). Tumour growth was monitored by measuring with a caliper the greatest longitudinal diameter (length) and the greatest transverse diameter (width). Tumour volumes were estimated by the modified ellipsoidal formula: tumour volume $=1 / 2\left(\right.$ length $\times$ width $\left.^{2}\right)$. Median tumour volume of each mouse group was compared (Bissery et al, 1991). Mice bearing tumours $>1500 \mathrm{~mm}^{3}$ were killed. The care and use of animals used here was strictly applying European and National Regulation for the Protection of Vertebrate Animals used for Experimental and other Scientific Purposes in force, and approved by the local Animal Welfare Body (AWB 022012).

Statistical analysis. Phenotypic data and animal studies were analysed using two-tailed Student's $t$-test and by repeatedmeasures ANOVA, respectively. The association between the clinical-pathological variables and mAb198.3 IHC staining was assessed with the two-sided Fisher's exact test. $P$-values $\leqslant 0.05$ were considered significant.

\section{RESULTS}

FAT1 is overexpressed in CRC. A mouse mAb (mAb198.3) directed against a FAT1 recombinant fragment was used in a preliminary screening of surgical formalin-fixed, paraffinembedded (FFPE) CRC samples from five patients. Three of five samples showed a clear membranous staining that extended in part to the cytoplasm, whereas normal colon samples from the same patients showed a negligible staining (Figure 1A). FAT1 differential expression in CRC was confirmed by an expanded IHC analysis of 49 patient samples. The protein appeared to be abundantly and homogeneously expressed at the level of the plasma membrane in cancer cells (39 out of 49 cases). Moreover, as CRC patients frequently develop metastasis, with liver being the most common site (40\%) (Pestana et al, 1964), we investigated FAT1 expression in liver samples with colon cancer metastasis from five patients. mAb198.3 detected FAT1 in all metastatic samples, showing a marked plasma membrane distribution in cancer cells and only a marginal background staining in normal hepatocytes surrounding the metastatic lesions (Figure 1A).

FAT1 prevalence in CRC. To study the prevalence of FAT1 and its potential clinical significance in CRC, IHC analysis was carried out on TMAs carrying 642 FFPE CRC samples (Supplementary
Table 1S). mAb198.3 gave a positive staining in 93\% CRC samples, with an intense or moderate staining in $47 \%$ of the cases. In $63 \%$ of FAT1-positive CRC samples, the staining mainly localised at the plasma membrane (homogeneous staining, generally moderate to strong intensity) and extended to the cytoplasm (Figure 1B, left panel). The remaining $37 \%$ of the positive CRC showed a weak cytoplasmic staining (Figure 1B, left panel). FAT1 staining pattern did not differ among the different histotypes of colon carcinoma. A correlation analysis with known clinical parameters and prognostic/predictive molecular features led to four main observations. First, we found that FAT1 is expressed in all CRC stages and grades, but at higher frequency in early $\mathrm{pT}$ stage and welldifferentiated CRC. FAT1 was detected in early (pT1 and pT2) and late (pT3 and pT4) CRCs with similar frequencies (intense/ moderate staining in $54 \%$ and $49 \%$ of early and late pT groups, respectively). However, pT1 CRC tended to be recognised by mAb198.3 with stronger intensity than CRC at more advanced stages ( $P$-value: 0.03) (Figure 1B, middle panel). Similarly, mAb198.3 recognised both poorly and well-differentiated CRCs, although a higher frequency and stronger staining intensity was found in welldifferentiated samples ( $P$-value: 0.02) (Figure 1B, right panel).

Second, we found that FAT1 expression/localisation was associated with the expression of E-cadherin. Analysis of 554 samples, which had been previously investigated for expression and localisation of E-cadherin and $\beta$-catenin (Tornillo et al, 2007), showed that FAT1 tends to accumulate at the level of the plasma membrane in CRC positive for E-cadherin (60.8\%), whereas in E-cadherin-negative CRC, FAT1 is present at similar frequency on the plasma membrane and in the cytoplasm (frequencies ranging from 33 to $46 \%$ ) (Figure 2A).

Third, we found that FAT1 expression in CRC was not linked to the activation status of the $\beta$-catenin pathway. Among our CRC samples, 192 had low $\beta$-catenin activation (intense/moderate $\beta$-catenin staining at the level of the plasma membrane and simultaneous weak/negative $\beta$-catenin staining in the nucleus), whereas 97 samples had high $\beta$-catenin activation (weak/negative $\beta$-catenin staining at the level of the plasma membrane and simultaneous intense/moderate $\beta$-catenin staining in the nucleus). We found that FAT1 expression and localisation does not significantly differ between CRC groups with high or low $\beta$-catenin activation (49.0\% and $46.4 \%$ plasma membrane positivity, $30.2 \%$ and $36.1 \%$ cytoplasmic positivity, respectively) (Figure 2B).

Fourth, and particularly interestingly, FAT1 was expressed in CRC regardless of the presence of mutations in KRAS and BRAF genes. KRAS gene sequence had been determined for 253 clinical samples, 171 of 253 CRCs had wild-type KRAS, whereas 82 samples carried one or two mutations, with G12D, G12V and G13D being the most frequent ones (Zlobec et al, 2010). FAT1 was detected with high frequency and expression level both in wildtype and mutant KRAS CRC (92.4\% and 93.9\%, respectively) (Figure 2C, right panel). Concerning $B R A F$, sequence data were available for 246 samples. BRAF was wild type in 220 samples, whereas it was mutated in the remaining 26 cases, primarily having the V600E substitution. FAT1 was detected with similar frequency and intensity in both populations ( $94.1 \%$ and $88.5 \%$, respectively) (Figure 2C, left panel).

FAT1 is detected intracellularly in colon precancerous states. The presence of FAT1 early-stage cancers was further confirmed by staining a TMA containing 159 colon adenomas of various histological grades and different histotypes, and 74 corresponding normal colon tissue samples. Approximately $90 \%$ of adenoma samples were stained, $60 \%$ with moderate or strong intensity (Supplementary Figure 1S). High-grade adenomas tended to have stronger staining than low-grade samples. Most adenoma samples (95.7\%) showed a cytoplasmic staining. Plasma membrane staining was detected in a low percentage $(4.3 \%)$ of adenoma samples 
A

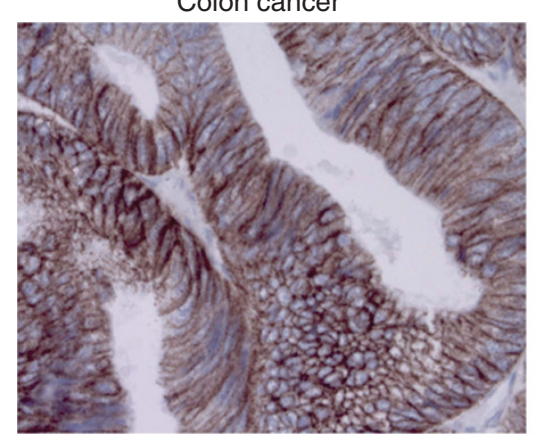

Liver metastasis

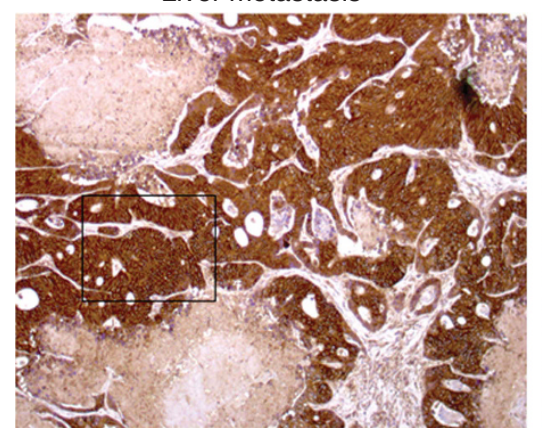

Normal colon

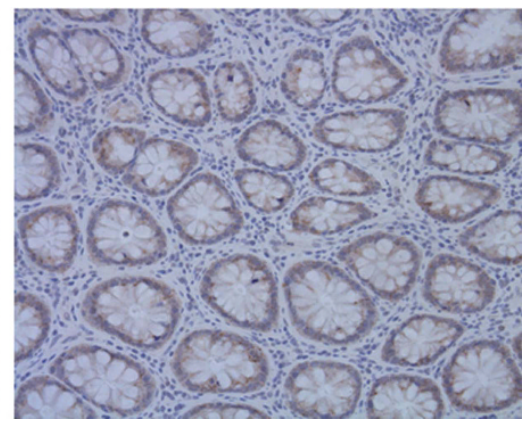

Zoomed view

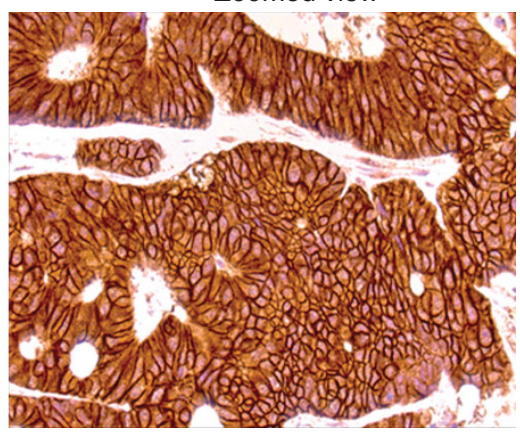

B

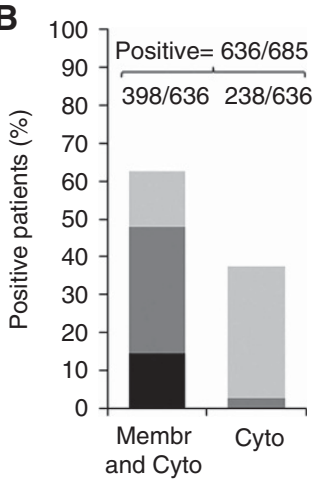

Cell localisation

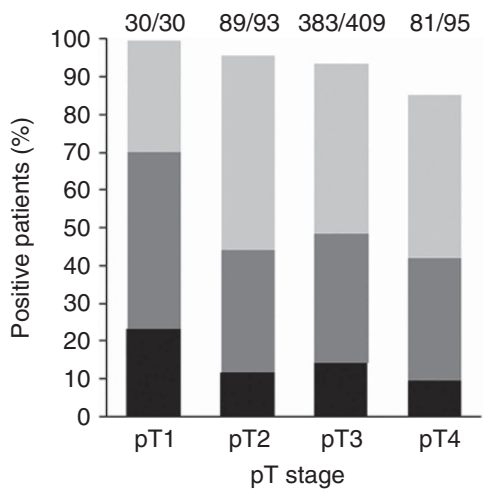

Intensity 1 Intensity 2

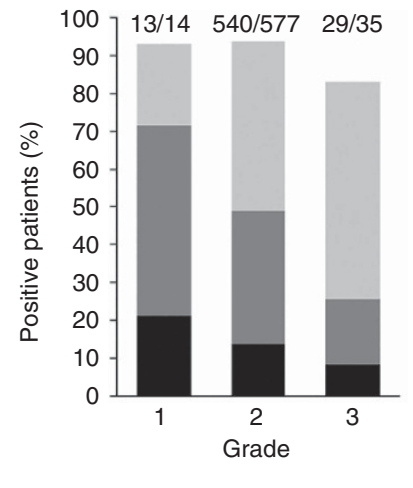

Intensity 3

Figure 1. FAT1 expression in CRC. (A) Immunostaining images of CRC and normal colon samples and liver metastasis from colon stained with mAb198.3. (B) FAT1 prevalence in CRC. Immunohistochemistry analysis vs cellular localisation (left panel), pT stage (centre panel) and grade (right panel). Histograms represent the FAT1 expression frequency. Above each bar is reported the number of CRC samples positive to the antibody/total. Membr, plasma membrane; Cyto, cytoplasm.

belonging to the subset of high-grade adenomas (Supplementary Figure 1S). Less than 5\% of normal colon samples showed a moderate or strong staining cytoplasmic, while the majority of them was negative or weakly stained (Supplementary Figure 1S).

mAb198.3 does not bind the plasma membrane of normal human cells. We investigated mAb198.3 reactivity in normal tissues by IHC using a TMA carrying normal tissues from 33 anatomical districts (MNO961). In most tissues, the staining was negligible or negative (Supplementary Figure 2S, panel A). In the normal ileum, a weak or moderate intracellular staining was detected. In the pancreas and bladder, a minimal intracellular staining was observed, limited to the pancreatic islets and urothelium, respectively. In kidney, stomach and breast tissues, the staining was confined to extracellular depositions. A significant intracellular staining was found in normal prostate, pituitary gland and skeletal muscle (Supplementary Figure 2S, panel A). Fluorescence-activated cell sorting analysis on mature human striated muscle cells differentiated from the primary human myoblast cell line (HSkM) gave negative results (not shown), further supporting the intracellular staining in the skeletal muscle. Finally, we investigated mAb198.3 surface binding on human peripheral blood lymphocytes (PBLs) purified from three healthy donors by FACS. The three PBL samples showed a negligible surface staining (Supplementary Figure 2S, panel B).

FAT1 is broadly expressed on the cell surface of colon cancer cell lines. mAb198.3 was used to detect FAT1 expression and localisation on the surface of a panel of colon cell lines, including the non-metastatic HCT15, HT29 and HCC2998 and the metastatic Colo205 and HCT116 by FACS and confocal microscopy, under conditions that preserve the plasma membrane integrity. Fluorescence-activated cell sorting analysis showed a clear surface staining in all tested colon cell lines (Figure 3A). In line with the FACS data, confocal microscopy analysis showed clear FAT1 detection at the plasma membrane of each tested cell 
A

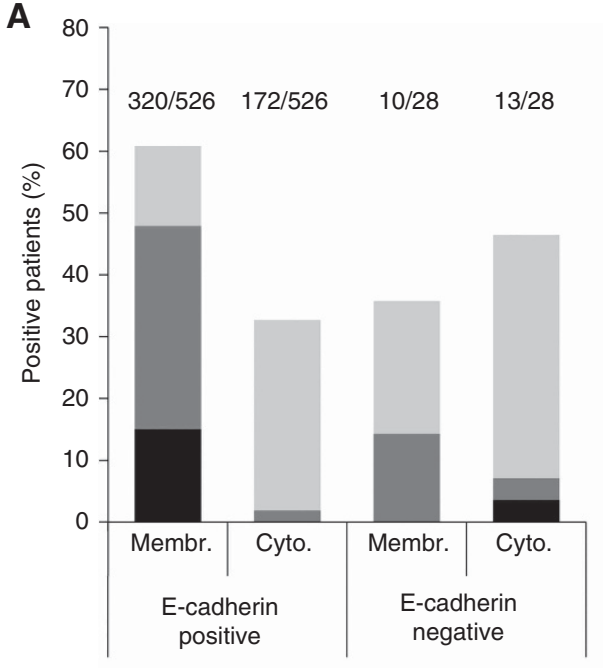

B

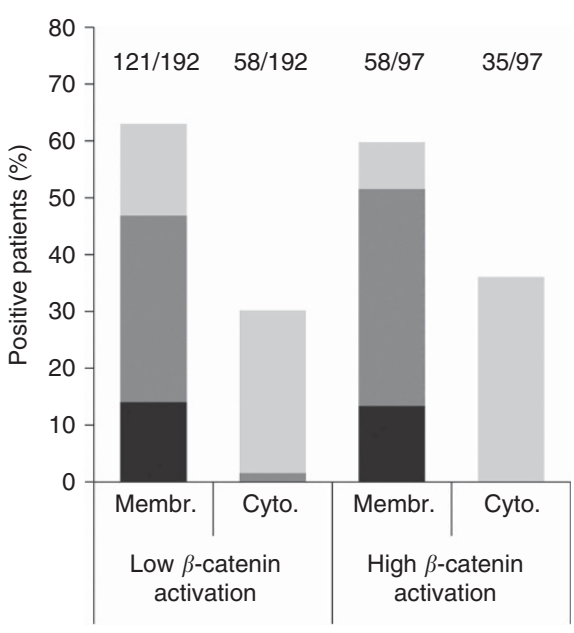

Intensity 3

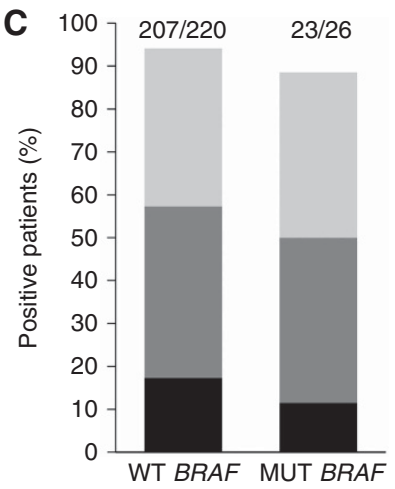

\begin{tabular}{|c|c|}
\hline $\begin{array}{c}\text { BRAF } \\
\text { mutations }\end{array}$ & FAT1 positive/total cases \\
\hline V600S & $0 / 1$ \\
\hline V600E & $21 / 23$ \\
\hline K601E & $2 / 2$ \\
\hline
\end{tabular}

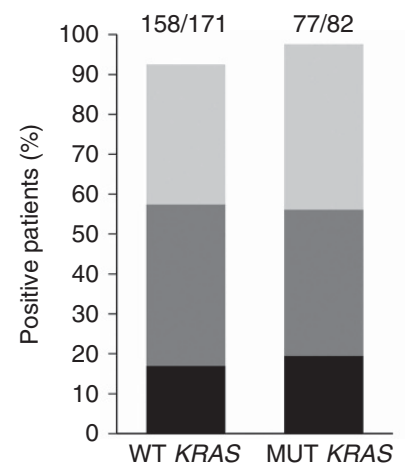

\begin{tabular}{|c|c|}
\hline $\begin{array}{c}\text { KRAS } \\
\text { mutations }\end{array}$ & FAT1 positive/total cases \\
\hline G12A & $5 / 5$ \\
\hline G12C & $2 / 2$ \\
\hline G12D & $33 / 34$ \\
\hline G12S & $3 / 3$ \\
\hline G12V & $15 / 16$ \\
\hline G12V-G13V & $1 / 1$ \\
\hline G13A & $2 / 2$ \\
\hline G13D & $17 / 17$ \\
\hline G13D-V14I & $0 / 0$ \\
\hline G13N & $1 / 1$ \\
\hline G13V & $1 / 1$ \\
\hline
\end{tabular}

Figure 2. FAT1 prevalence compared with E-cadherin and $\beta$-catenin expression, KRAS and BRAF mutations. (A and B) FAT1 detection frequency and cell localsation detected by mAb198.3 in relation to E-cadherin and $\beta$-catenin activation. (C) FAT1 detection frequency in CRC cases bearing wild-type and mutant BRAF (left panel) and KRAS (right panel). Tables below each graph report the mutations found in the CRC samples.

line (Figure 3B). FAT1 distribution at the level of the plasma membrane was quite homogeneous, partially overlapping with E-cadherin and $\beta$-catenin staining (63\% and $57 \%$, respectively) (Figure 3F). Western blot analysis of total cell extracts showed the presence of a pattern of high MW bands above $200 \mathrm{kDa}$ likely generated by proteolytic processing and/or degradation of the giant protein (Figure 3C). FAT1 recognition by mAb198.3 was markedly reduced in both FACS and WB assays on cell lines treated with FAT1-specific siRNAs (Figure 3, panels D and E).

FAT1 depletion reduces invasiveness but it does not interfere with apoptosis. The influence of FAT1 on apoptosis and invasiveness was assessed in colon cancer cell lines treated with FAT1-specific siRNAs as compared with control samples treated with irrelevant siRNAs. Apoptosis was measured by the Annexin V-PI staining in FAT1-silenced cells, as such or after overnight incubation with the death receptor-mediated apoptosis TRAIL (100 $\mathrm{ng} \mathrm{ml}^{-1}$ ) (Ganten et al, 2006). FAT1 silencing did not alter the percentage of apoptotic cells (Supplementary Figure 3S, panel A), and it did not influence the sensitivity to TRAIL (Supplementary Figure 3S). Finally, the effect of FAT1 silencing in cell invasiveness was assessed by the Boyden assay. Loss of FAT1 markedly reduced HCT15-invasive phenotype compared with control samples (Figure 3G).

mAb198.3 recognises two similar epitopes on the extracellular domain of FAT1. mAb198.3 recognises a recombinant domain (from aa 723 to 1352) of the extracellular region of FAT1. To better 

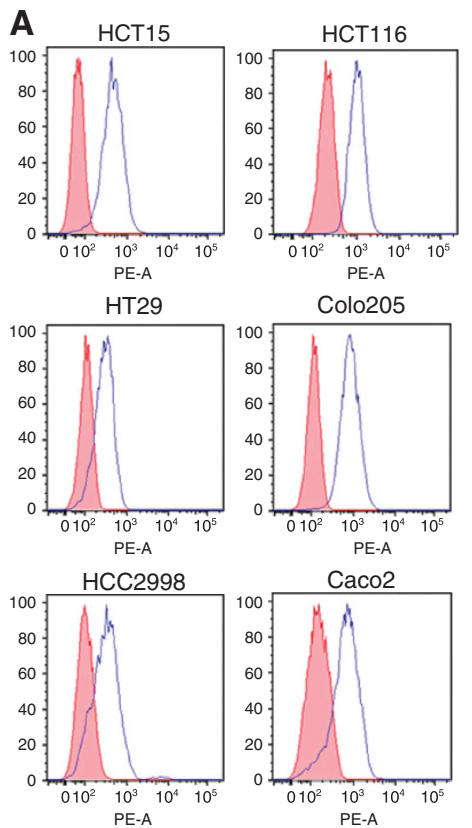

C

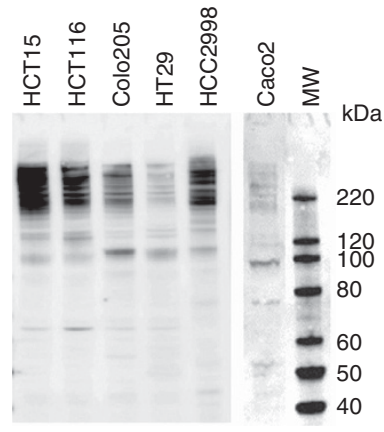

mAb198.3
B

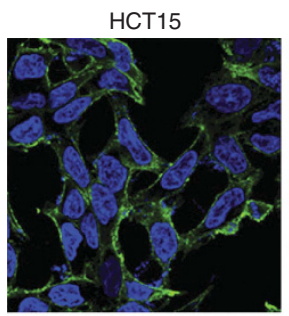

Colo205

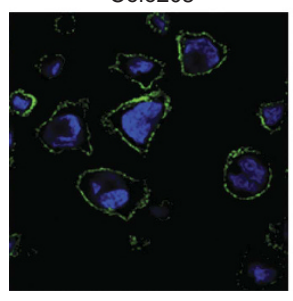

HCT116

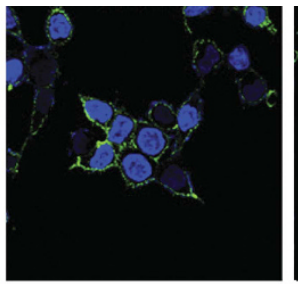

HCC2998

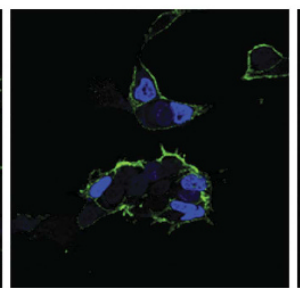

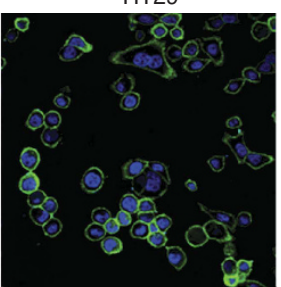

Caco2

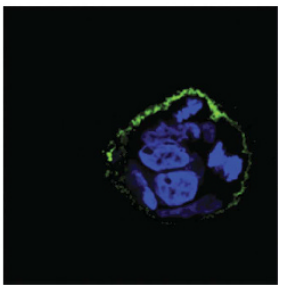

E

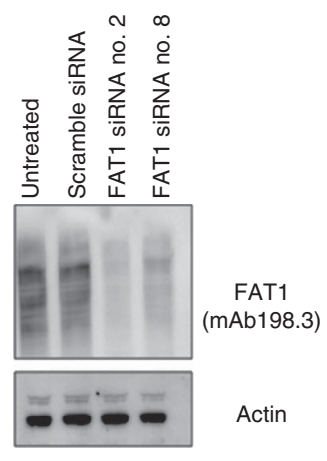

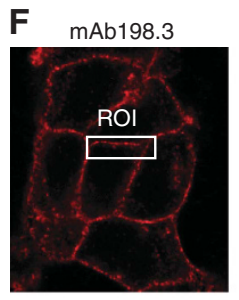

mAb198.3

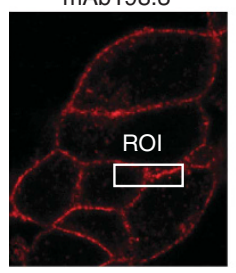

D

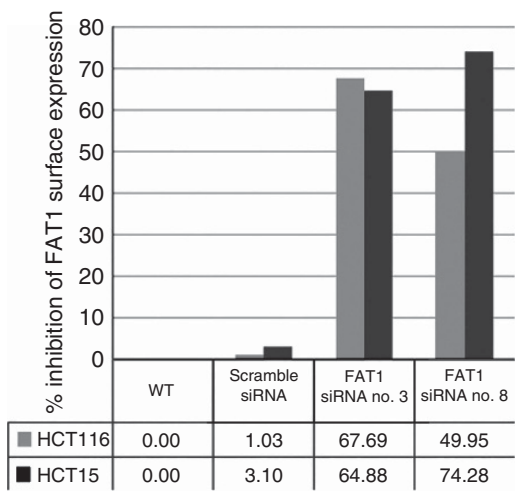

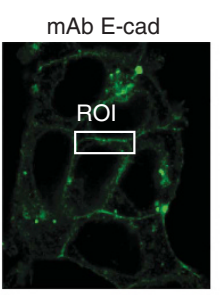

$\mathrm{mAb} \beta$-cat

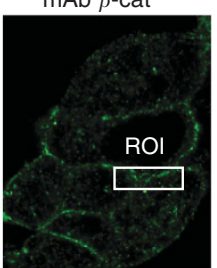

Merge

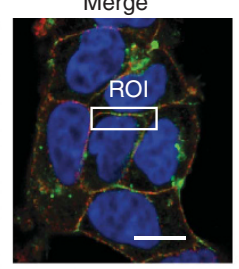

Merge

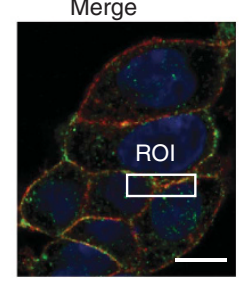

Colocalisation

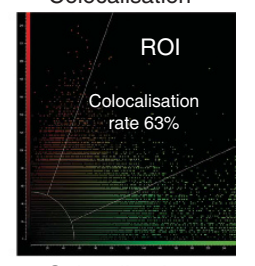

Colocalisation

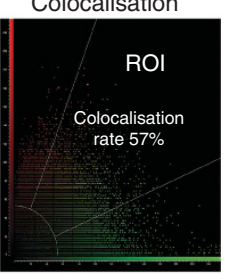

G

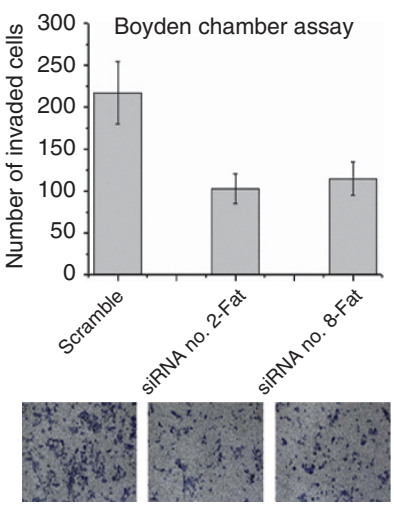

Figure 3. FAT1 expression, localisation and involvement in the invasiveness of colon cancer cells. (A) Cell surface detection of FAT1 by FACS analysis. Staining of colon cancer cell lines using mAb198.3 (empty blue peak) or isotype control (filled red peak) and detected by PE-labelled goat anti-mouse antibodies. (B) Plasma membrane detection by confocal microscopy. Fixed cells preincubated with the mAb198.3 were stained with AlexaFluor 488-labelled goat anti-mouse antibodies to detect FAT1 (green) and DAPI (4',6-diamidino-2-phenylindole) to visualise nuclei (blue). (C) Western blot analysis. Cell total extracts were separated on SDS-PAGE (25 $\mu \mathrm{g}$ per lane) and subjected to immunoblot using mAb198.3. (D) mAb198.3 cell surface specificity was assessed by FAT1 silencing in HCT15 and HCT116 cells. (E) FAT1 silencing assessment by WB in HCT15 cell extracts immunostained with mAb198.3 or anti-actin as control. (F) Colocalisation of FAT1 with E-cadherin and $\beta$-catenin by confocal microscopy. HCT15 cells were coincubated with mAb 198.3 and anti-E-cadherin or anti- $\beta$-catenin rabbit antibodies and detected with AlexaFluor 594-labelled goat anti-mouse or with AlexaFluor 488-labelled goat anti-rabbit antibodies. (G) Invasiveness evaluation by the Boyden assay. HCT cells migrated towards the lower surface of the chamber filters were counted after Diff-Quick staining. 
define the specificity of the antibody, we first performed WB analysis of HeLa cells transfected with plasmids encoding different overlapping FAT1 fragments encompassing the region used as an immunogen. mAb198.3 recognised two fragments, one including the cadherin domain 8 (D8) (from aa 823 to 927) and the other cadherin domain 12 (D12) (from aa 1242 to 1352) (Figure 4A). The antibody binding was also confirmed by WB on purified recombinant D8 and D12 (rD8 and rD12). Recombinant D8 was bound with an approximately two-fold higher affinity than $\mathrm{rD} 12$ $\left(K_{\mathrm{D}}: 9.52 \mathrm{E}^{-09}\right.$ vs $\left.1.82 \mathrm{E}^{-08} \mathrm{M}\right)$, as judged by plasmon surface resonance experiments on the recombinant domains on the solid phase. Domains 8 and 12 showed an amino-acid identity of only $16 \%$ on the entire region and revealed a shorter stretch of 18 aa with 67\% identity (Figure 4E). To test whether the mAb198.3 binding epitope could fall within this region, seven 25-mer partially overlapping peptides were synthetised on D8 and D12 domains (covering the highly homologous stretch) and tested for their ability to compete with mAb198.3 binding in ELISA, FACS and IHC compared with an irrelevant peptide. Enzyme-linked immunosorbent assay plates were coated with purified $\mathrm{rD} 8$ and rD12 and coincubated with mAb198.3 and different peptide concentrations (from 0.01 to $100 \mu \mathrm{g} \mathrm{ml}^{-1}$ ). Two peptides, peptide 7 (IQVEATDKDLGPNGHVTYSIVTDTD) and peptide 1 (REPLYHVIATDKDEGPNAEISYSIE), designed on D8 and D12 sequences, respectively, were able to inhibit the antibody binding on both domains (Figure 4B). When used in FACS competition analysis, both peptides significantly reduced the antibody binding on the cell surface of HCT15 and Colo205 cells (Figure 4C). In both assays peptide 7 showed the highest competing activity. Finally, the two peptides were also tested in an IHC competition assay. Coincubation of mAb198.3 $\left(2.5 \mu \mathrm{g} \mathrm{ml}^{-1}\right)$ with peptides 7 $\left(50 \mu \mathrm{g} \mathrm{ml}^{-1}\right)$ almost abolished the mAb198.3 recognition of colon cancer cells, whereas peptide 1 significantly reduced it (Figure 4D). The two competing peptides share a stretch of 11 aa (VEATDKDLGPN) with $81 \%$ identity (Figure 4E).

mAb198.3 is efficiently internalised by cancer cells and is amenable to ADC development. mAbs suitable for the development of ADC must have the property of being internalised within cancer cells through the process of receptor-mediated endocytosis, thus bringing its toxic payload into the cells. We tested the mAb198.3 potential as ADC by assessing its internalisation property on FAT1-positive colon cell lines. HCT15, HCT116 and Colo205 were incubated with mAb198.3 at $4{ }^{\circ} \mathrm{C}$, then shifted at $37^{\circ} \mathrm{C}$ and finally the loss of surface antibody staining and the concomitant intracellular accumulation of the immune complexes were monitored by flow cytometry and confocal microscopy. Fluorescence-activated cell sorting analysis showed that after $1 \mathrm{~h}$ at $37^{\circ} \mathrm{C}$, the antibody binding on the cell surface was reduced by $\sim 50 \%$, and after $2 \mathrm{~h}$, it almost disappeared from the cell surface (Figure 5A). Confocal microscopy analysis showed that loss of mAb198.3 from the cell surface was paralleled by the formation of intracellular immune complexes, visible as vesicle structures moving from the cell membrane to the perinuclear region (Figure 5B). Similar internalisation results were obtained with HCC2998, Caco2 and HT29 (not shown). We then investigated whether the antibody has the capacity to deliver toxins inside the cells by using an in vitro killing assay using DM1 toxin conjugated to protein $\mathrm{G}$ using a non-cleavable chemistry. HCT15 cells were incubated at $37^{\circ} \mathrm{C}$ with different concentrations of $\mathrm{mAb} 198.3$ or an isotype-matched control mAb (from 3 to $80 \mathrm{nM}$ ), in the presence of Protein G-DM1, and cell killing was estimated after $72 \mathrm{~h}$ by luminescence reading. The coincubation of mAb198.3 with Protein G-DM1 induced a significant killing of HCT15 cells (Figure 5C).

The anti-FAT1 mAb198.3 reduces cancer growth in colon xenograft model. We investigated the mAb198.3 ability to reduce tumour growth in subcutaneous xenograft models, both in preventive and therapeutic experimental settings. In preventive setting, HCT15 cells were engrafted in immune-deficient athymic mice. Mice were injected intravenously with repeated doses of the anti-FAT1 mAb198.3 starting from the day before the cancer cell inoculation and continuing for $\sim 4$ weeks. At the end of treatment, mAb198.3 reduced the median tumour volume by $\sim 45 \%$ compared with the untreated or isotype control mAb (Figure 6A). In the therapeutic setting, mAb198.3 was administered repeatedly in mice bearing either HCT15 or HT29 xenograft of $\sim 100 \mathrm{~mm}^{3}$. At the end of treatment, the antibody was able to reduce the tumour burden by $30-50 \%$ (Figure 6B). Moreover, near-infrared (NI) optical imaging of the IR800-labelled antibodies showed that NI staining mostly accumulated in the tumour area, with marginal crossreactivity in other anatomical districts (Supplementary Figure 4S).

\section{DISCUSSION}

FAT1 appears to have multiple, seemingly opposing roles in development and in cell growth. The multifaceted FAT1 functions can explain its controversial role in cancer, as it appears to act as tumour suppressor or tumour promoter in a context-dependent manner (Katoh, 2012). In many tumours, FAT1 is reported as a tumour suppressor, including oral cancer, astrocytoma, glioblastoma and ductal carcinoma (Settakorn et al, 2005; Nakaya et al, 2007; Chosdol et al, 2009). In cholangiocarcinoma, FAT1 shows a reduced plasma membrane localisation (Settakorn et al, 2005) and in invasive breast cancer it is preferentially downregulated (Kwaepila et al, 2006). By contrast, in acute myeloid leukaemia, pre-B-acute lymphoblastic leukaemia (ALL) and T-ALL (de Bock et al, 2012), FAT1 has been described to act as a tumour promoter. The molecular basis of FAT1 multiple role in cancer could result from a balance among different molecular interactions, likely altered by gene mutations. Recent studies link FAT1 to E-cadherin and Wnt/ $\beta$-catenin pathways (Morris et al, 2013a, b). Loss of E-cadherin-mediated cell adhesion can promote $\beta$-catenin signalling where cytoplasmic $\beta$-catenin translocates to the nucleus and functions as an activator for T-cell factor/lymphoid enhancer factor transcription factors, resulting in a subset of cellular effects involving cellular adhesion, tissue morphogenesis and tumour development. The expression levels of E-cadherin and membrane $\beta$-catenin are often inversely correlated with tumour malignancy. The FAT1 ICD binding to $\beta$-catenin could be responsible for the FAT1 growth-suppressive effects. Loss of FAT1 or mutations in the ICD may affect FAT1 interaction with $\beta$-catenin, consequently unleash $\beta$-catenin-dependent transcriptional activity and upregulate progrowth Wnt targets (Morris et al, 2013a). Indeed, FAT1 mutations found in different cancers are now considered drivers of aberrant activation of the Wnt signalling pathway.

The present study contributes to our current knowledge on the role of FAT1 in cancer. By an extensive IHC study using an antiFAT1 $\mathrm{mAb}$, we discovered that the protein is highly expressed in a large fraction of CRC, mainly detected on the plasma membrane. High FAT1 expression is more frequently found in the initial stage - low-grade CRC. Nevertheless, the protein is also well expressed in a significant percentage of late-stage and poorly differentiated CRC. An IHC analysis of FAT1 staining in precancerous lesions, such as adenoma at different histological differentiation grades, confirmed the aberrant FAT1 expression detected in early CRC. In the large majority of adenoma samples, FAT1 was detected intracellularly with the tendency of high-grade adenomas to show a higher expression of the protein than low-grade samples, and a small percentage of the high-grade samples also showing plasma membrane staining. These preliminary results provide the rationale 
A

\begin{tabular}{|c|c|c|}
\hline$\sum_{\text {Cadherin }}$ & EGF-like Laminin & Transmembrane \\
\hline $\begin{array}{c}\text { Recombinant } \\
\text { fragments }\end{array}$ & $\begin{array}{l}\text { Cadherin } \\
\text { domains }\end{array}$ & $\begin{array}{c}\text { Western } \\
\text { blot }\end{array}$ \\
\hline $\begin{array}{l}\text { D no. } 7-12 \\
\text { (aa } 723-1352 \text { ) }\end{array}$ & $2^{7} 82^{8}=101112$ & Positive \\
\hline $\begin{array}{l}\text { D no. 7-11 } \\
\text { (aa } 723-1245 \text { ) }\end{array}$ & $\begin{array}{l}7891011 \\
7\end{array}$ & Positive \\
\hline $\begin{array}{l}\text { D no. } 12 \\
\text { (aa 1242-1352) }\end{array}$ & $\sum^{12}$ & Positive \\
\hline $\begin{array}{l}\text { D no. 8-11 } \\
\text { (aa } 823-1245 \text { ) }\end{array}$ & $\begin{array}{l}891011 \\
2\end{array}$ & Positive \\
\hline $\begin{array}{l}\text { D no. 10-11 } \\
\text { (aa 1041-1245) }\end{array}$ & $\stackrel{10}{211}$ & Negative \\
\hline $\begin{array}{l}\text { D no. } 7-9 \\
\text { (aa } 723-1040)\end{array}$ & $\begin{array}{lll}7 & 8 & 9 \\
2 & 2 & \end{array}$ & Positive \\
\hline $\begin{array}{l}\text { D no. } 9 \\
\text { (aa 927-1040) }\end{array}$ & $\sum^{9}$ & Negative \\
\hline $\begin{array}{l}\text { D no. } 8 \\
\text { (aa 823-927) }\end{array}$ & 8 & Positive \\
\hline
\end{tabular}
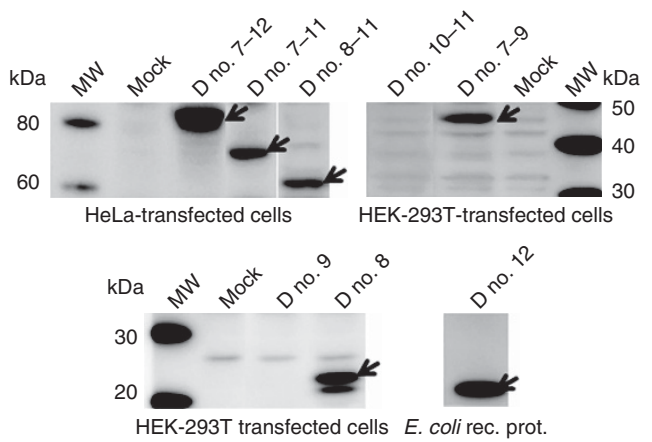

C
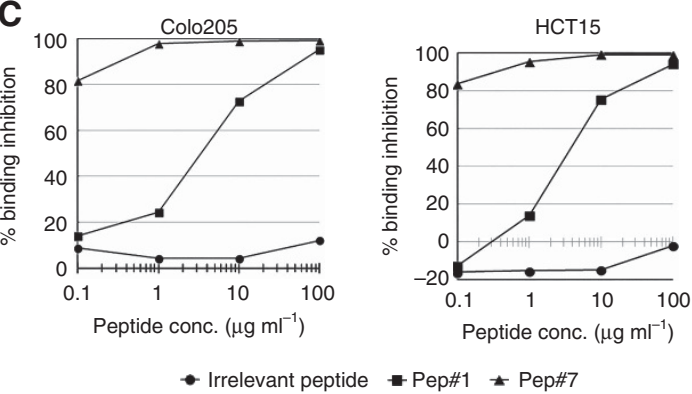

- Irrelevant peptide -Pep\#1 —Pep\#7
B
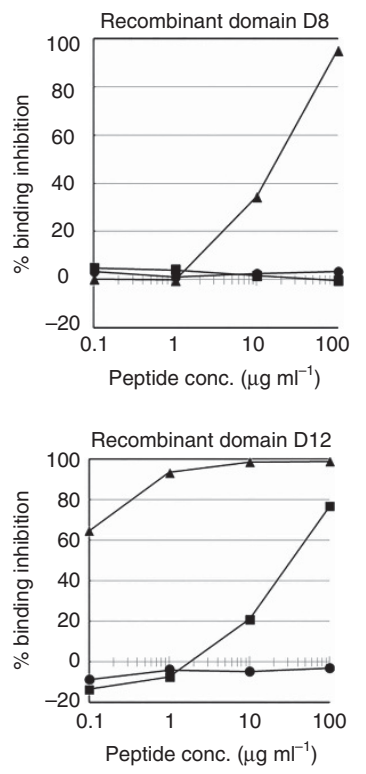

- Irrelevant peptide - Pep no. 1

Ł Pep no. 7

D

mAb198.3 + irrelevant peptide

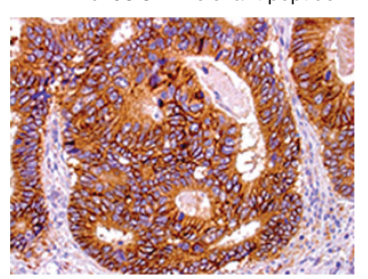

mAb198.3 + peptide 1

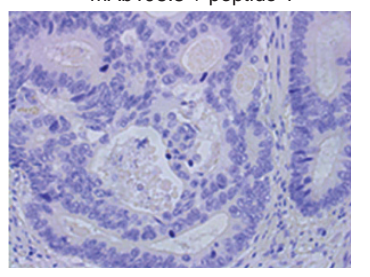

mAb198.3 + peptide 7

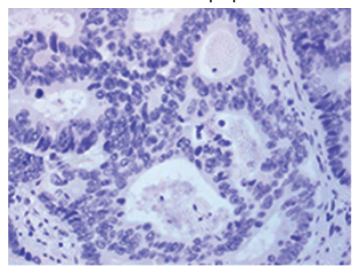

E

Conservation

FAT1 D no. 8 823.......... LQESYFVEVSEDKEVHSE I I QVEATDKDLGPNGHVTYSIVTDTDTFS ID 871 FAT1D no. 121242 KPQFLQKFYKIRLPEREKPDRERNARREPLYHVIATDKDEGPNAEISYS IEDGNEHGKFF 1301

Conservation

FAT1D no. 8 872 SVTG VVN İARLDRELQHEHSLKI EARDQAREEPQLFS̈TVVVKVSLEDVNDNPPTF 927

FAT1 D n. 121302 I EPKTGVVSSKRFSAAGEYDIL S I KAVDNGRPQKS STTRLH I EWI SKPKPS..... 1352

Figure 4. FAT1 domain/epitope specificity of mAb198.3. (A) Scheme of FAT1 constructs generated to identify the mAb198.3 epitope. Below the scheme are reported the WB of HeLa and HEK-293T cells transfected with the FAT1 constructs or the D12 domain expressed in E. coli. (B) Enzyme-linked immunosorbent assay peptide competition analysis: ELISA plates coated with rD8 and rD12 were coincubated with mAb198.3 and different concentrations of the 25 mer peptides 1 and 7 or an irrelevant peptide. The binding inhibition was measured as compared with samples incubated with mAb198.3 alone. (C and D) Fluorescence-activated cell sorting and IHC peptide competition analysis on HCT15 cells or colon cancer tissues, respectively, incubated with mAb198.3 and the 25 mer peptides 1 or 7 and the irrelevant peptide. (E) Sequence alignment of the FAT1 domains D8 and D12 containing the mAb198.3 epitope. The consensus is reported above the alignment. The peptides 7 and 1 are highlighted. 

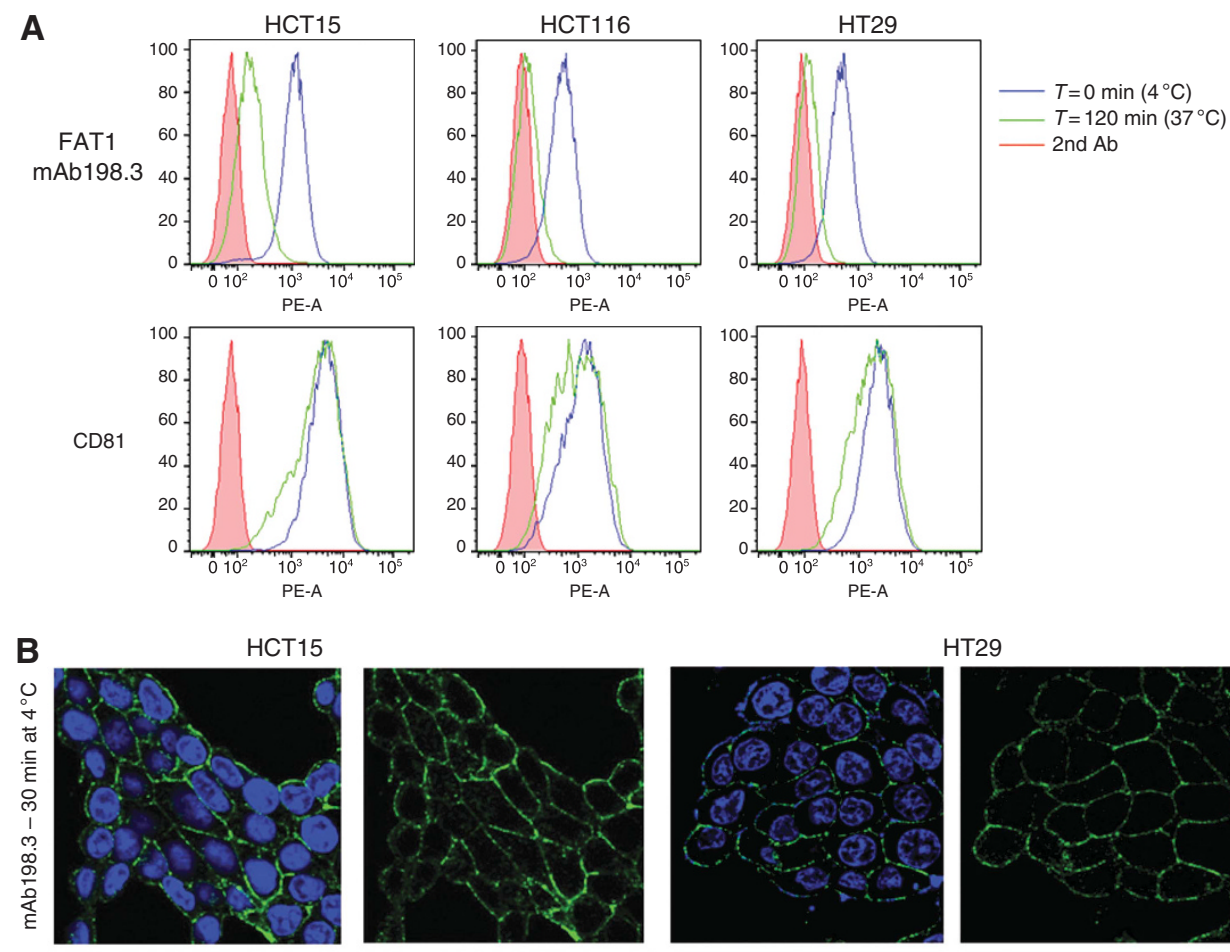

HT29
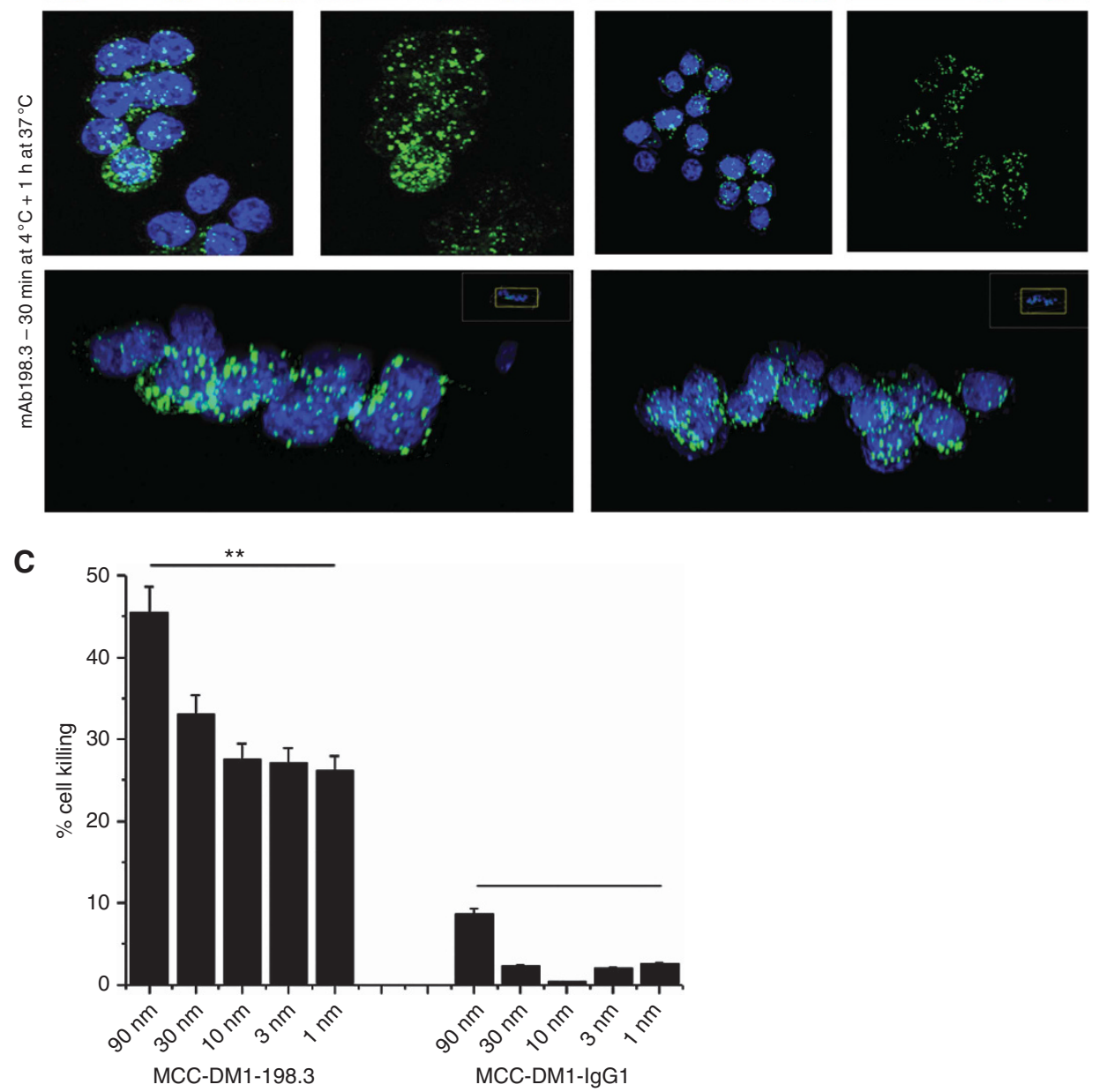

Figure 5. mAb198.3 internalisation and drug delivery in colon cancer cell lines. (A and B) mAb198.3 internalisation. Colon cancer cell lines were incubated for $30 \mathrm{~min}$ at $4{ }^{\circ} \mathrm{C}$ with mAb198.3, then washed and finally shifted at $37^{\circ} \mathrm{C}$. After $2 \mathrm{~h}$ incubation at $37^{\circ} \mathrm{C}, \mathrm{mAb} 198.3$ disappearance from the cell surface was assessed by FACS (A) and confocal microscopy (B) as compared with cells maintained at $4{ }^{\circ} \mathrm{C}$. (C) Drug delivery indirect assay. HCT15 cell were incubated with mAb198.3 or an isotype control in the presence of the protein-G-MCC-DM1 conjugates. Cell killing was assessed after $72 \mathrm{~h}$ by luminescence assay. 

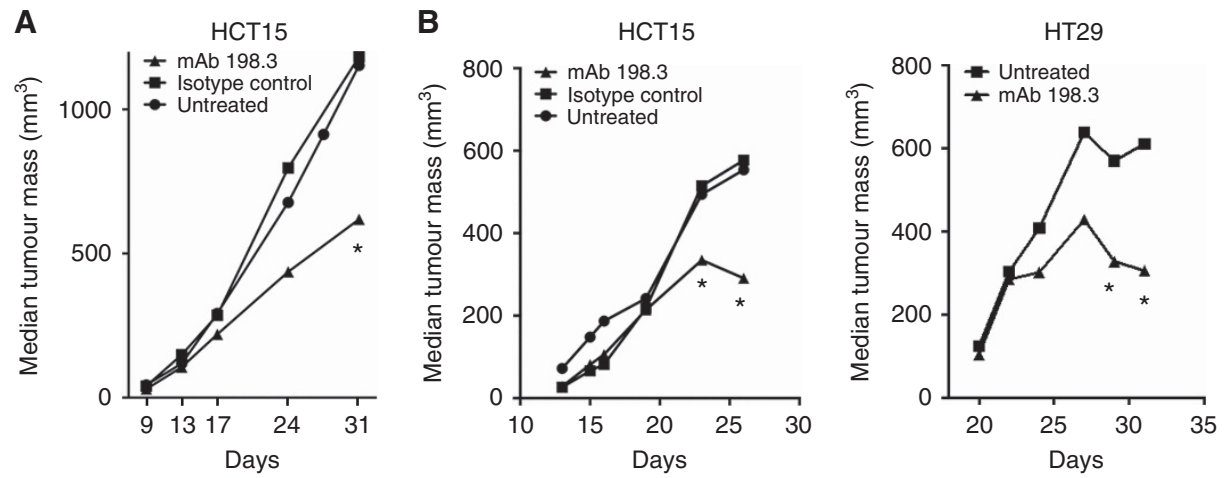

Figure 6. mAb198.3 efficacy in colon cancer xenografts. (A) Preventive model. Athymic mice were engrafted subcutaneously with HCT15 cells and treated intravenously two times a week with $12 \mathrm{mg}$ mAb per $\mathrm{kg}$ of mAb198.3 or isotype control mAb, or untreated. (B) Therapeutic model. mAb198.3 was administered repeatedly in athymic mice bearing either HCT15 or HT29 xenograft of $\sim 100 \mathrm{~mm}^{3}$. Median tumour volumes of each mAb-treated and -untreated mouse group are shown.

for further studies aimed at assessing the FAT1 potential as a predictive factor for cancer onset.

Our IHC data provide new insights into the relation of FAT1 with E-cadherin and $\beta$-catenin expression in CRC.

In line with previous evidence, we found high FAT1 expression and plasma membrane localisation in CRC-expressing E-cadherin and plasma membrane $\beta$-catenin, features associated with lower cancer malignancy, suggesting that in these samples FAT1 could contribute to the cell contact. However, FAT1 expression and plasma membrane localisation is high also in CRC with high activation of the $\beta$-catenin pathway and in metastatic CRC. Overall, the data suggest that in CRC FAT1 is expressed regardless of the activation of the $\beta$-catenin pathway. Such conclusion is also supported by the evidence that FAT1 mutations have been reported to occur in only $7.7 \%$ of CRCs (Morris et al, 2013a, b), while we detected FAT1 in over $90 \%$ of CRCs. Among the possible alternative roles of FAT1 in cancer, its proteolytic processing is an aspect under scrutiny. In normal keratinocytes, a furin-mediated processing generates two FAT1 fragments of 430 (N-term) and $85 \mathrm{kDa}$ (C-term) that form a non-covalent heterodimer. Conversely, in melanoma and pancreatic cancers FAT1 undergoes an aberrant processing (Sadeqzadeh et al, 2011; Wojtalewicz et al, 2014), in which a furin-independent processing generates a product of $65 \mathrm{kDa}$ no longer in association with the extracellular fragment. Moreover, as it is known that FAT1 ICD is able to enter the nucleus and could modulate downstream modulators (Magg et al, 2005), it is possible that an alternative FAT1 processing could alter its signalling activity. Our preliminary data indicate that, as in pancreatic cancer (Wojtalewicz et al, 2014), in CRC FAT1 is cleaved by the ADAM10 protease, as silencing of ADAM10 in HCT15 cells induces the accumulation of unprocessed FAT1 protein (not shown).

Another important indication of FAT1 role in cancer is that it is involved in cell invasiveness. Indeed, we show that loss of FAT1 significantly reduces the invasive phenotype of colon cancer cells. A similar phenotype was observed in the glioblastoma (Dikshit et al, 2012). This evidence would suggest that FAT1 is involved in tumour progression and possibly in epithelial-mesenchymal transition. Additional IHC analysis needs to be carried out to support this hypothesis, by assessing FAT1 expression in budding cells localised the infiltrating tumour border.

Moreover, differently from glioblastoma (Kranz and Boutros, 2014), we show that in CRC cells FAT1 is not involved in apoptosis and it does not influence the sensitivity to TRAIL-mediated apoptosis. Overall, the data suggest that FAT1 role in apoptosis might change in a context-dependent manner.
The present study describes a murine mAb (mAb198.3) that specifically recognises FAT1-expressing CRC. This $\mathrm{mAb}$ has a limited crossreactivity in normal human tissues and PBLs. When present, the mAb reactivity is confined to the intracellular compartment. These results are of particular relevance in view of a possible exploitation of mAb198.3 in human therapy. Remarkably, mAb198.3 specifically recognises FAT1 on the surface of colon cancer lines as judged by FACS and confocal microscopy, combined to gene silencing. The $\mathrm{mAb}$ recognises the cadherin domains D8 and D12, with binding affinities in the low nanomolar range. Its binding epitope maps within a sequence of 25 aa, which shows a stretch of 18 identical amino acids between the two domains, as judged by peptide competition assays. Since published genetic studies (http://cancergenome.nih.gov/) do not report mutations in the domains targeted by mAb198.3, we hypothesise that the reactivity of the antibody on cancer cells is ascribable to structural alteration of the epitope, possibly due to aberrant FAT1 processing or post-translational modifications. The elucidation of the FAT1 aberrant expression in CRC will deserve dedicated studies.

Finally, we provide experimental evidence that mAb198.3 has therapeutic potential. First, we showed that systemic administration of the antibody reduced cancer growth both in a preventive and in a therapeutic murine cancer xenograft models. Considering that mAb198.3 belongs to the IgG1 immunoglobulin subclass, known to be ineffective in promoting activation of complementdependent cytotoxicity and antibody-dependent cellular cytotoxicity (ADCC) (Reichert, 2011), our working hypothesis is that the mechanism of mAb198.3-mediated tumour inhibition could be due to interference with the FAT1 signalling pathway. In vitro experiments showed that mAb198.3 was able to moderately reduce proliferation of colon cancer cells lines (not shown), suggesting that additional regulatory events or microenvironmental stimuli might enhance mAb198.3 activity or influence FAT1 expression/ accessibility in vivo. Experiments aimed at elucidating these aspects are deserved. In our future activities, mAb198.3 will be subjected to humanisation and optimisation. For instance, it would be interesting to test whether humanisation and switching to an isotype endowed with ADCC activity could increase mAb198.3 antitumour activity. If such improvements will be achieved, it will be important to test the therapeutic activity of the optimised antibody in more advanced cancer models, such as patient-derived xenografts or model of liver metastasis. Second, we found that mAb198.3 is as a potential component of ADC. Antibody-drug conjugates represent an emerging therapeutic modality that, being conjugated to a cytotoxic payload, can potentially reduce the toxicities and improve the therapeutic indices of 
conventional anticancer antibodies. Kadcyla and Adcetris are two ADC molecules approved by the FDA, and many more are currently in clinical development. A requirement for ADC is efficient $\mathrm{mAb}$ internalisation in cancer cells. In this study, we showed that mAb198.3 is efficiently internalised, and when coincubated with DM1-protein-G, it induces significant cell killing.

This result strongly suggests that mAb198.3 is amenable to ADC development and provides the basis to a systematic screening of linker-payload conjugation chemistry. Additional studies after humanisation/optimisation of mAb198.3 are deserved to characterise the internalisation property of the FAT1 antibody. A last remark is that FAT1 is expressed in CRC, regardless of the mutational state of KRAS and BRAF genes. KRAS and BRAF mutations (occurring in $30-40 \%$ and $10 \%$ of CRC, respectively) are two acknowledged predictive factors for the resistance to the antiEGFR antibodies therapies (Ihle et al, 2012; Yokota, 2012). In this scenario, mAb198.3 could open new possibilities for the treatment of CRC.

\section{ACKNOWLEDGEMENTS}

We thank Prof. Luisa Bracci for Plasmon Surface Resonance analysis and interesting discussion. The study was funded by Regione Toscana and European grants.

\section{CONFLICT OF INTEREST}

The authors declare no conflict of interest.

\section{REFERENCES}

Bissery MC, Guénard D, Guéritte-Voegelein F, Lavelle F (1991) Experimental antitumor activity of taxotere (RP 56976, NSC 628503), a taxol analogue. Cancer Res 51: 4845-4852.

de Bock CE, Ardjmand A, Molloy TJ, Bone SM, Johnstone D, Campbell DM, Shipman KL, Yeadon TM, Holst J, Spanevello MD, Nelmes G, Catchpoole DR, Lincz LF, Boyd AW, Burns GF, Thorne RF (2012) The Fatl cadherin is overexpressed and an independent prognostic factor for survival in paired diagnosis-relapse samples of precursor B-cell acute lymphoblastic leukemia. Leukemia 26: 918-926.

Chosdol K, Misra A, Puri S, Srivastava T, Chattopadhyay P, Sarkar C, Mahapatra AK, Sinha S (2009) Frequent loss of heterozygosity and altered expression of the candidate tumor suppressor gene 'FAT' in human astrocytic tumors. BMC Cancer 9: 5.

Ciardiello F, Kim N, Saeki T, Dono R, Persico MG, Plowman GD, Garrigues J, Radke S, Todaro GJ, Salomon DS (1991) Differential expression of epidermal growth factor-related proteins in human colorectal tumors. Proc Natl Acad Sci USA 88: 7792-7796.

Dikshit B, Irshad K, Madan E, Aggarwal N, Sarkar C, Chandra PS, Gupta DK, Chattopadhyay P, Sinha S, Chosdol K (2012) FAT1 acts as an upstream regulator of oncogenic and inflammatory pathways, via PDCD4, in glioma cells. Oncogene 32: 1-11.

Dunne J, Hanby AM, Poulsom R, Jones TA, Sheer D, Chin WG, Da SM, Zhao Q, Beverley PC, Owen MJ (1995) Molecular cloning and tissue expression of FAT, the human homologue of the Drosophila fat gene that is located on chromosome 4q34-q35 and encodes a putative adhesion molecule. Genomics 30: 207-223.

Ferlay J, Parkin DM, Steliarova-Foucher E (2010) Estimates of cancer incidence and mortality in Europe in 2008. Eur J Cancer 46: 765-781.

Ganten TM, Koschny R, Sykora J, Schulze-Bergkamen H, Büchler P, Haas TL, Schader MB, Untergasser A, Stremmel W, Walczak H (2006) Preclinical differentiation between apparently safe and potentially hepatotoxic applications of TRAIL either alone or in combination with chemotherapeutic drugs. Clin Cancer Res 12: 2640-2646.
Grifantini R, Pagani M, Pierleoni A, Grandi A, Parri M, Campagnoli S, Pileri P, Cattaneo D, Canidio E, Pontillo A, De Camilli E, Bresciani A, Marinoni F, Pedrazzoli E, Nogarotto R, Abrignani S, Viale G, Sarmientos P, Grandi G (2011) A novel polyclonal antibody library for expression profiling of poorly characterized, membrane and secreted human proteins. J Proteomics 75: 532-547.

Hagan S, Orr MCM, Doyle B (2013) Targeted therapies in colorectal cancer - an integrative view by PPPM. EPMA J 4: 3 .

Ihle NT, Byers LA, Kim ES, Saintigny P, Lee JJ, Blumenschein GR, Tsao A, Liu S, Larsen JE, Wang J, Diao L, Coombes KR, Chen L, Zhang S, Abdelmelek MF, Tang X, Papadimitrakopoulou V, Minna JD, Lippman SM, Hong WK, Herbst RS, Wistuba, Heymach JV, Powis G (2012) Effect of KRAS oncogene substitutions on protein behavior: implications for signaling and clinical outcome. J Natl Cancer Inst 104: 228-239.

Katoh M (2012) Function and cancer genomics of FAT family genes (Review). Int J Oncol 41: 1913-1918.

Kononen J, Bubendorf L, Kallioniemi A, Bärlund M, Schraml P, Leighton S, Torhorst J, Mihatsch MJ, Sauter G, Kallioniemi OP (1998) Tissue microarrays for high-throughput molecular profiling of tumor specimens. Nat Med 4: 844-847.

Kranz D, Boutros M (2014) A synthetic lethal screen identifies FAT1 as an antagonist of caspase-8 in extrinsic apoptosis. EMBO J 33: 181-197.

Kwaepila N, Burns G, Leong AS-Y (2006) Immunohistological localisation of human FAT1 (hFAT) protein in 326 breast cancers. Does this adhesion molecule have a role in pathogenesis? Pathology 38: 125-131.

Magg T, Schreiner D, Solis GP, Bade EG, Hofer HW (2005) Processing of the human protocadherin Fat1 and translocation of its cytoplasmic domain to the nucleus. Exp Cell Res 307: 100-108.

Moeller MJ, Soofi A, Braun GS, Li X, Watzl C, Kriz W, Holzman LB (2004) Protocadherin FAT1 binds Ena/VASP proteins and is necessary for actin dynamics and cell polarization. EMBO J 23: 3769-3779.

Morris LGT, Kaufman AM, Gong Y, Ramaswami D, Walsh LA, Turcan Ş, Eng S, Kannan K, Zou Y, Peng L, Banuchi VE, Paty P, Zeng Z, Vakiani E, Solit D, Singh B, Ganly I, Liau L, Cloughesy TC, Mischel PS, Mellinghoff IK, Chan TA (2013a) Recurrent somatic mutation of FAT1 in multiple human cancers leads to aberrant Wnt activation. Nat Genet 45: 253-261.

Morris LGT, Ramaswami D, Chan TA (2013b) The FAT epidemic: a gene family frequently mutated across multiple human cancer types. Cell Cycle 12: 1011-1012.

Nakaya K, Yamagata HD, Arita N, Nakashiro K-I, Nose M, Miki T, Hamakawa $H$ (2007) Identification of homozygous deletions of tumor suppressor gene FAT in oral cancer using CGH-array. Oncogene 26: $5300-5308$.

O'Connell JB, Maggard MA, Ko CY (2004) Colon cancer survival rates with the new American Joint Committee on Cancer sixth edition staging. J Natl Cancer Inst 96: 1420-1425.

Parri M, Pietrovito L, Grandi A, Campagnoli S, De Camilli E, Bianchini F, Marchiò S, Bussolino F, Jin B, Sarmientos P, Grandi G, Viale G, Pileri P, Chiarugi P, Grifantini R (2014) Angiopoietin-like 7, a novel proangiogenetic factor over-expressed in cancer. Angiogenesis 17: 881-896.

Pestana C, Reitemeier RJ, Moertel CG, Judd ES, Dockerty MB (1964) The natural history of carcinoma of the colon and rectum. Am J Surg 108: 826-829.

Reichert JM (2011) Antibody-based therapeutics to watch in 2011. MAbs 3: 76-99.

Sadeqzadeh E, de Bock CE, Zhang XD, Shipman KL, Scott NM, Song C, Yeadon T, Oliveira CS, Jin B, Hersey P, Boyd AW, Burns GF, Thorne RF (2011) Dual processing of FAT1 cadherin protein by human melanoma cells generates distinct protein products. J Biol Chem 286: 28181-28191.

Settakorn J, Kaewpila N, Burns GF, Leong AS-Y (2005) FAT, E-cadherin, beta catenin, HER 2/neu, Ki67 immuno-expression, and histological grade in intrahepatic cholangiocarcinoma. J Clin Pathol 58: 1249-1254.

Song C, Yan B, Chen L, Li Y, Wei Y, Sun Y, Yang A, Yang K, Jin B (2009) Novel immunohistochemical monoclonal antibody against rat $\mathrm{B}$ cell receptor associated protein 31 (BAP31). Hybridoma (Larchmt) 28: 363-367.

Tanoue T, Takeichi M (2004) Mammalian Fat1 cadherin regulates actin dynamics and cell-cell contact. J Cell Biol 165: 517-528.

Tornillo L, Lugli A, Zlobec I, Willi N, Glatz K, Lehmann F, Spichtin H-P, Maurer R, Stoios D, Sauter G, Terracciano L (2007) Prognostic value of 
cell cycle and apoptosis regulatory proteins in mismatch repair-proficient colorectal cancer: a tissue microarray-based approach. Am J Clin Pathol 127: $114-123$.

Wojtalewicz N, Sadeqzadeh E, Weiß JV, Tehrani MM, Klein-Scory S, Hahn S, Schmiegel W, Warnken U, Schnölzer M, de Bock CE, Thorne RF, Schwarte-Waldhoff I (2014) A soluble form of the giant cadherin Fat1 is released from pancreatic cancer cells by ADAM10 mediated ectodomain shedding. PLoS One 9: e90461.

Yokota T (2012) Are KRAS/BRAF mutations potent prognostic and/or predictive biomarkers in colorectal cancers? Anticancer Agents Med Chem 12: $163-171$.
Zlobec I, Kovac M, Erzberger P, Molinari F, Bihl MP, Rufle A, Foerster A, Frattini M, Terracciano L, Heinimann K, Lugli A (2010) Combined analysis of specific KRAS mutation, BRAF and microsatellite instability identifies prognostic subgroups of sporadic and hereditary colorectal cancer. Int J Cancer 127: 2569-2575.

This work is published under the standard license to publish agreement. After 12 months the work will become freely available and the license terms will switch to a Creative Commons AttributionNonCommercial-Share Alike 4.0 Unported License.

Supplementary Information accompanies this paper on British Journal of Cancer website (http://www.nature.com/bjc) 